\title{
Applying new clinicopathological characteristics to prognostication in advanced thyroid carcinoma
}

\author{
Maria E Cabanillas and Steven I Sherman
}

From the Department of Endocrine Neoplasia and Hormonal Disorders, The University of Texas MD Anderson Cancer Center, 1515 Holcombe, Unit 1461, Houston, Texas 77030, USA

(Correspondence should be addressed to M E Cabanillas; Email: mcabani@mdanderson.org)

\begin{abstract}
In the February 2011 issue of Endocrine-Related Cancer, Deandreis et al. reported that increased FDG uptake was prognostic in patients with metastatic thyroid cancer. Fludeoxyglucose-positron emission tomography (FDG-PET) is routinely used in the staging and follow-up of patients with cancer. This study gives further evidence for the role of FDG-PET scanning in metastatic thyroid cancer, especially to identify patients with aggressive disease requiring systemic therapy.
\end{abstract}

Endocrine-Related Cancer (2012) 19 C19-C22

\section{Introduction}

Thyroid cancer is now the fifth most commonly diagnosed cancer in women and is the ninth in overall incidence in the USA (American Cancer Society 2010). The most common form of thyroid cancer, differentiated thyroid cancer (DTC), is derived from the follicular cells of the thyroid and includes papillary, follicular, and Hurthle cell thyroid cancers. The prognosis for the majority of DTC patients is excellent, as most patients treated with surgery with or without adjuvant radioiodine (RAI) are cured or have indolent residual disease. However, a subset of patients present with or eventually develop metastatic disease that lacks the ability to trap RAI or is no longer responsive to this treatment. Conventional chemotherapy has not proven effective in DTC, as response rates are around $25 \%$ at best. During the past decade, great strides have been made in discovering effective treatments with several tyrosine kinase inhibitors, targeted against the vascular epithelial growth factor receptor (VEGFR), as well as kinases in the mitogen-activated protein kinase (MAPK) pathway. The challenge, however, lies in identifying the subpopulation of patients who may benefit from systemic therapies due to their more aggressive disease course as distinct from those for whom chemotherapy can be deferred or avoided. The tyrosine kinase inhibitors, initially thought to have fewer and more manageable side effects than conventional chemotherapy, can have a spectrum of adverse effects ranging from bothersome, but manageable, to serious and life threatening. Furthermore, due to the chronicity of their use, the side effects of tyrosine kinase inhibitors (TKI) may have serious impact on long-term quality of life. Additionally, treatment costs can exceed thousands of dollars per month so the decision to initiate therapy should not be taken lightly. The standard way of approaching clinical trial design in metastatic thyroid cancer is to restrict entry to patients who have RAI-negative or -refractory disease and to those who have progression over a fixed period of time. NCCN guidelines currently recommend tyrosine kinase inhibitor therapy for patients with progressive metastatic disease if the patient is unwilling or unable to enter a clinical trial (Sherman et al. 2009).

\section{Metabolic patterns}

In their paper, Deandreis et al. (2011) studied the correlation between histological and immunohistochemical patterns and survival outcomes, in addition to metabolic patterns (i.e. fludeoxyglucose (FDG) and RAI uptake) in 80 patients with metastatic DTC who had available tissue from the primary tumor. Although 
these parameters have all been studied and reported previously, no one has reported a comprehensive analysis of all of them together. Using multivariate analysis, the authors found that FDG-avid disease on positron emission tomography (PET) scanning was the only significant prognostic factor for overall survival (OS). Patients with FDG-PET-negative disease had a 2 -year OS of $100 \%$ vs only $60 \%$ in patients with FDGPET-positive disease. Among patients who had FDGPET-positive disease, OS decreased with the number of FDG-avid lesions and with increasing metabolic activity (SUV (standardized uptake value)). These findings are consistent with a large retrospective study previously reported by Robbins et al. (2006), where the authors identified that the aggressiveness of therapy matched the FDG-PET results.

Taken together, the two studies call into question how we decide which patients to treat with systemic agents and how we design clinical trials for thyroid cancer. FDG-PET scanning has not been standard practice to predict prognosis or to determine which patients should be treated with systemic therapies either on clinical trials or outside of trials. To our knowledge, only one published study used FDG-PET avidity as an entry criterion instead of progression by standard radiographic criteria, such as response evaluation criteria in solid tumors (RECIST) (Carr et al. 2010). In this trial, 35 patients with metastatic, RAI-refractory DTC or medullary thyroid carcinoma were eligible if they had SUV uptake in a tumor lesion and measurable disease by RECIST. Progressive disease was not an inclusion criterion. As an exploratory endpoint, patients underwent a follow-up FDG-PET/CT after 1 week of continuous therapy with sunitinib, an oral multi-kinase inhibitor of vascular endothelial growth factor (VEGFR), RET, plateletderived growth factor receptor (PDGFR), and c-kit, among others. An association between average SUV percent change after 1 week and eventual tumor response was found. Risk of tumor progression increased by $4 \%$ for every $1 \%$ increase in average SUV from baseline. We applaud Carr et al.'s effort to include patients with FDG-avid disease in clinical trials. Development of trials in this fashion could avoid delays in treatment while we continue the standard of 'watch and wait' for progression in all others, a practice that causes anxiety for both patient and doctor. This is especially true with patients who have bulky disease where waiting for the disease to progress sufficiently for trial entry could prove detrimental. Unfortunately, Deandreis et al. (2011) failed to look at this subset of patients with bulky disease to determine whether the PET scan can identify those with no uptake as a favorable group, but at least one study has shown volume of FDG-avid lesions to be highly significant for survival (Wang et al. 2000).

\section{Pathologic and mutational patterns}

Consistent with the literature (Volante et al. 2004, Hiltzik et al. 2006, Rivera et al. 2008), the authors found that patients with poorly differentiated thyroid cancer (PDC) had more necrosis and mitoses in the primary tumor; however, this was also found in some well-differentiated papillary and follicular thyroid cancers. The presence of necrosis was found to be highly predictive for shortened progression-free survival in multivariate analysis. Fifty percent of patients with necrosis and $10 \%$ without necrosis in primary tumor progressed in 1 year. In this series, necrosis was not predictive of OS, but others have reported a strong correlation (Rivera et al. 2008). Necrosis is an underrecognized predictor of clinical outcome and is not included in the most commonly used TNM staging system. There is no standard method used by pathologists for reporting the percentage of necrosis found in the tumor, yet this may be an important histological finding that, in conjunction with FDG-PET status, could guide timing of systemic therapies once radioactive iodine is no longer effective.

Kinase-activating mutations in the $B R A F$ protooncogene are found in up to $40 \%$ of primary PTC tumors (Elisei et al. 2008) and up to $70 \%$ of recurrent papillary thyroid carcinomas (PTC) (Henderson et al. 2009). Mutations in codon 600 of the $B R A F$ gene lead to downstream activation of MEK and ERK, resulting in cell proliferation and survival. Many others have shown that BRAF mutations correlate with adverse clinicopathological features and that these patients have earlier recurrences. Deandreis et al. (2011) reported only three patients with the BRAF V600E mutation in the primary tumor. All the three patients demonstrated FDG-avid metastases and none died during the follow-up period. The low frequency of $B R A F$ V600E mutations in the primary tumors begs the question of whether the metastatic sites carry mutations that differ from those in the primary tumors. Discordance between the primary and metastatic site and even within the thyroid gland has previously been reported in patients with multifocal papillary thyroid cancer (Giannini et al. 2007, Jovanovic et al. 2008). From a research perspective, it is therefore reasonable to study tissue from the metastatic sites for mutations such as BRAF V600E, especially in patients with multifocal tumors. High incidence of $B R A F$ and $B R A F$ plus $R E T / P T C$ rearrangements has been reported in a 
series of recurrent thyroid cancer (Henderson et al. 2009). RAS mutations have also been found in welldifferentiated and more commonly in poorly DTCs (Garcia-Rostan et al. 2003), suggesting that the tumor may acquire more mutations as the disease progresses. $R A S$ mutations may also confer a worse prognosis (Garcia-Rostan et al. 2003). Thus, other somatic mutations that may coexist with $B R A F$ should also be studied further in the research setting. Certainly, the field of oncology has been moving toward understanding the molecular derangements in the tumor and using more targeted therapies. This practice has proven fruitful in other malignancies such as $B R A F$-mutated melanomas (Chapman et al. 2011), GIST tumors, and acute and chronic leukemias. Restricting enrollment to patients with a particular mutation or rearrangement targeted by the drug increases the response rates significantly in tumor types such as lung cancer (Lynch et al. 2004, Paez et al. 2004, Pao et al. 2004, Kwak et al. 2010) and melanoma (Flaherty et al. 2010), and certainly future studies in thyroid cancer, which selectively target these mutations, should include only patients with confirmed somatic mutations. In addition, trials should include molecular studies of the metastatic tumor for the mutation being targeted as well as other mutations that are common in thyroid cancer, particularly in patients who do not respond to the therapy.

\section{Future directions}

Interest in studying newer therapies for metastatic thyroid cancer has brought hope to patients with this disease. As supported by the paper of Deandreis et al. (2011), future trials should be designed using available evidence regarding high-risk patients namely those with multiple FDG-avid lesions, high SUVs, tumor necrosis, and mutations in the metastatic tumor who may benefit the most from therapy. While obtaining tumor from metastatic sites is difficult, it is not impossible and will help us understand who will be most likely to respond to therapy. Whether FDG-PET can be used to predict response and survival during therapy is under investigation and we are anxiously waiting for the results of trials seeking to answer this question.

\section{Declaration of interest}

The authors declare that there is no conflict of interest that could be perceived as prejudicing the impartiality of the research reported.

\section{Funding}

This research did not receive any specific grant from any funding agency in the public, commercial or not-for-profit sector.

\section{References}

American Cancer Society 2010 In Cancer Facts \& Figures 2010. American Cancer Society: Atlanta, GA, USA.

Carr LL, Mankoff DA, Goulart BH, Eaton KD, Capell PT, Kell EM, Bauman JE \& Martins RG 2010 Phase II study of daily sunitinib in FDG-PET-positive, iodine-refractory differentiated thyroid cancer and metastatic medullary carcinoma of the thyroid with functional imaging correlation. Clinical Cancer Research 16 5260-5268. (doi:10.1158/1078-0432.CCR-10-0994)

Chapman PB, Hauschild A, Robert C, Haanen JB, Ascierto P, Larkin J, Dummer R, Garbe C, Testori A, Maio M et al. 2011 Improved survival with vemurafenib in melanoma with BRAF V600E mutation. New England Journal of Medicine 364 2507-2516. (doi:10.1056/NEJMoa1103782)

Deandreis D, Al Ghuzlan A, Leboulleux S, Lacroix L, Garsi JP, Talbot M, Lumbroso J, Baudin E, Caillou B, Bidart JM et al. 2011 Do histological, immunohistochemical, and metabolic (radioiodine and fluorodeoxyglucose uptakes) patterns of metastatic thyroid cancer correlate with patient outcome? Endocrine-Related Cancer 18 159-169. (doi:10.1677/ERC-10-0233)

Elisei R, Ugolini C, Viola D, Lupi C, Biagini A, Giannini R, Romei C, Miccoli P, Pinchera A \& Basolo F 2008 BRAF(V600E) mutation and outcome of patients with papillary thyroid carcinoma: a 15-year median follow-up study. Journal of Clinical Endocrinology and Metabolism 93 3943-3949. (doi:10.1210/jc.2008-0607)

Flaherty KT, Puzanov I, Kim KB, Ribas A, McArthur GA, Sosman JA, O’Dwyer PJ, Lee RJ, Grippo JF, Nolop K et al. 2010 Inhibition of mutated, activated BRAF in metastatic melanoma. New England Journal of Medicine 363 809-819. (doi:10.1056/NEJMoa1002011)

Garcia-Rostan G, Zhao H, Camp RL, Pollan M, Herrero A, Pardo J, Wu R, Carcangiu ML, Costa J \& Tallini G 2003 Ras mutations are associated with aggressive tumor phenotypes and poor prognosis in thyroid cancer. Journal of Clinical Oncology 21 3226-3235. (doi:10. 1200/JCO.2003.10.130)

Giannini R, Ugolini C, Lupi C, Proietti A, Elisei R, Salvatore G, Berti P, Materazzi G, Miccoli P, Santoro M et al. 2007 The heterogeneous distribution of BRAF mutation supports the independent clonal origin of distinct tumor foci in multifocal papillary thyroid carcinoma. Journal of Clinical Endocrinology and Metabolism 92 3511-3516. (doi:10.1210/jc.2007-0594)

Henderson YC, Shellenberger TD, Williams MD, El-Naggar AK, Fredrick MJ, Cieply KM \& Clayman GL 2009 High rate of BRAF and RET/PTC dual mutations associated 
with recurrent papillary thyroid carcinoma. Clinical Cancer Research 15 485-491. (doi:10.1158/1078-0432. CCR-08-0933)

Hiltzik D, Carlson DL, Tuttle RM, Chuai S, Ishill N, Shaha A, Shah JP, Singh B \& Ghossein RA 2006 Poorly differentiated thyroid carcinomas defined on the basis of mitosis and necrosis: a clinicopathologic study of 58 patients. Cancer 106 1286-1295. (doi:10.1002/cncr. 21739)

Jovanovic L, Delahunt B, McIver B, Eberhardt NL \& Grebe SK 2008 Most multifocal papillary thyroid carcinomas acquire genetic and morphotype diversity through subclonal evolution following the intra-glandular spread of the initial neoplastic clone. Journal of Pathology 215 145-154. (doi:10.1002/path.2342)

Kwak EL, Bang YJ, Camidge DR, Shaw AT, Solomon B, Maki RG, Ou SH, Dezube BJ, Janne PA, Costa DB et al. 2010 Anaplastic lymphoma kinase inhibition in non-small-cell lung cancer. New England Journal of Medicine 363 1693-1703. (doi:10.1056/ NEJMoa1006448)

Lynch TJ, Bell DW, Sordella R, Gurubhagavatula S, Okimoto RA, Brannigan BW, Harris PL, Haserlat SM, Supko JG, Haluska FG et al. 2004 Activating mutations in the epidermal growth factor receptor underlying responsiveness of non-small-cell lung cancer to gefitinib. New England Journal of Medicine 350 2129-2139. (doi:10. 1056/NEJMoa040938)

Paez JG, Janne PA, Lee JC, Tracy S, Greulich H, Gabriel S, Herman P, Kaye FJ, Lindeman N, Boggon TJ et al. 2004 EGFR mutations in lung cancer: correlation with clinical response to gefitinib therapy. Science 304 1497-1500. (doi:10.1126/science.1099314)

Pao W, Miller V, Zakowski M, Doherty J, Politi K, Sarkaria I, Singh B, Heelan R, Rusch V, Fulton L et al. 2004 EGF receptor gene mutations are common in lung cancers from "never smokers" and are associated with sensitivity of tumors to gefitinib and erlotinib. PNAS 101 13306-13311. (doi:10.1073/pnas.0405220101)

Rivera M, Ghossein RA, Schoder H, Gomez D, Larson SM \& Tuttle RM 2008 Histopathologic characterization of radioactive iodine-refractory fluorodeoxyglucose-positron emission tomography-positive thyroid carcinoma. Cancer 113 48-56. (doi:10.1002/cncr.23515)

Robbins RJ, Wan Q, Grewal RK, Reibke R, Gonen M, Strauss HW, Tuttle RM, Drucker W \& Larson SM 2006 Real-time prognosis for metastatic thyroid carcinoma based on 2-[18F]fluoro-2-deoxy-D-glucose-positron emission tomography scanning. Journal of Clinical Endocrinology and Metabolism 91 498-505. (doi:10. 1210/jc.2005-1534)

Sherman SI, Tuttle RM, Ball DW, Byrd D, Clark OH, Daniels GH, Dilawari RA, Doherty GM, Ehya H, Farrar WB et al. 2009 NCCN practice guidelines in oncology: thyroid carcinoma 1.2009. Journal of the National Comprehensive Cancer Network 1-91. (www.nccn.org)

Volante M, Cavallo GP \& Papotti M 2004 Prognostic factors of clinical interest in poorly differentiated carcinomas of the thyroid. Endocrine Pathology 15 313-317. (doi:10. 1385/EP:15:4:313)

Wang W, Larson SM, Fazzari M, Tickoo SK, Kolbert K, Sgouros G, Yeung H, Macapinlac H, Rosai J \& Robbins RJ 2000 Prognostic value of [18F]fluorodeoxyglucose positron emission tomographic scanning in patients with thyroid cancer. Journal of Clinical Endocrinology and Metabolism 85 1107-1113. (doi:10.1210/jc.85.3.1107)

Received in final form 5 January 2012

Accepted 11 January 2012

Made available online as an Accepted Preprint 12 January 2012 